\title{
Cacti and Their Uses
}

\author{
A Discussion of This Interesting Family and Some of the Things It Is Good For
}

By Dr. William A. Murrill, New York Botanical Garden

Photographs by courtesy of the United States National Museum

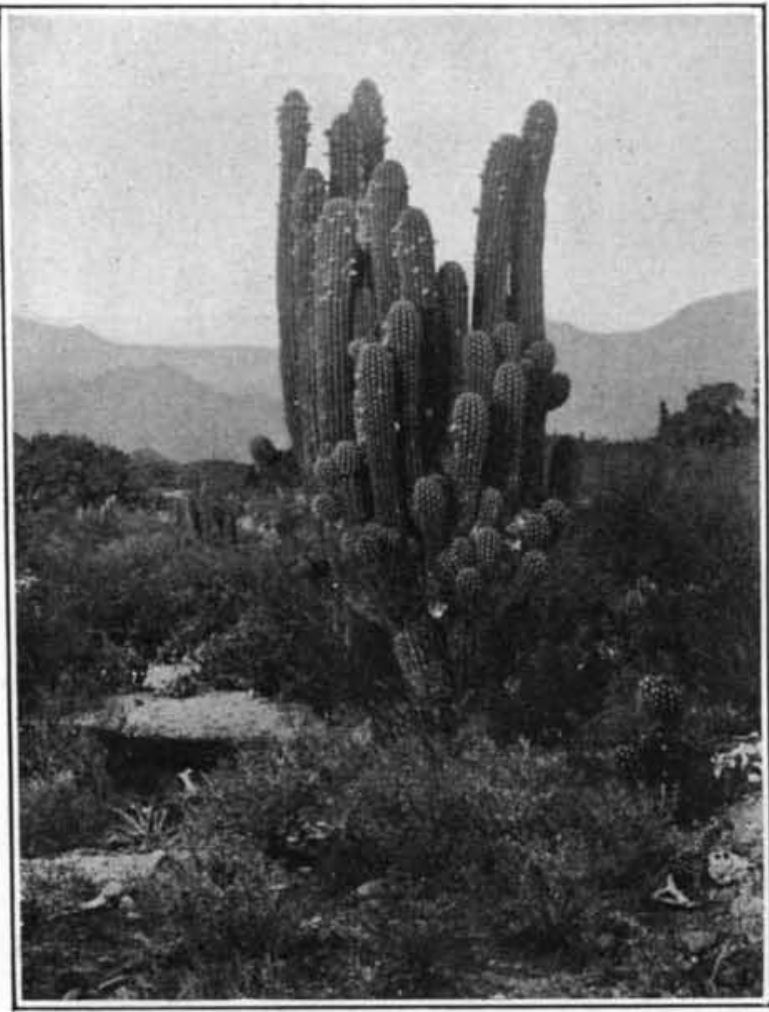

A desert is not necessarily a monotonous waste

$T$ is estimated that there are three billion acres of desert land in the world; and, if these unattractive and unproductive wastes are ver to.."blossom like the rose," it will be the cacti or plants similarly adapted to desert conditions that will furnish the flowers. Desert plants were like other plants once, but the vital necessity for preserving moisture gradually wrought a wonderful change in their appearance and structure. Few of the cacti now have any conspicuous leaves, their place being taken by flattened joints, or pads, which are modified portions of the stem; and even the sap has become mucilaginous or milks, preventing the pe arious shape and sizes serve to protect them against grazing animals that are often killed when driven by hunger and thirst to devour these plants in spite of their spines. The few forms of spineless cacti that occur in the wild stat always frequent rocky ledges and other situation that are inaccessible to most animals, if not. to all The number of species of cacti recognized is large amounting to about one thousand, and half of these are found in Mexico. They vary from tiny plants no bigger than one's finger to trees sixty feet in height, present ing all manner of queer and interesting shapes and furnishing the botanist with no end of knotty problems. Extensive collections of living plants may be seen under glass at the New York Botanical Garden, the Department of Agriculture in Washington, and the Missouri Botanical Garden in St Louis ; while others in the open are to be found at Riverside, California in the open are to be found at Riverside, California; Texas; Miami, Florida; and elsewhere.

Cactus plants are certainly not ornamental in the ordinary sense, but beauty is rêtative. A forest of giant cactus trees stretching mile after mile in the desert with nothing to rival them may be decidedly attrackive. In Mexico the cactus ornaments the national banner and is stamped on many of the older coins, while in Arizona and New Mexico it has been selected as the state flower

The cactus family is noted for the magnificence of its flowers, which are usually large, often fragrant, wide spreading or tubular, diurnal or nocturnal, evanescent or persistent, and vary in color from white, yellow, or orange to rose-colored, deep-red, or purple. Thè calyx and corolla are not distinct, but the numerous stamens in the center are often differently colored and lend an added charm to the flower. The fruit is often brilliantly colored, highly ornamental as well as useful, and lasts for a long time.

The cactus plant has indirectly added much to the attractiveness of certain manufactured garments by supporting the cochineal insect, from which the famous cochineal dye is made. This insect occurs on a species of Opuntia, the cochineal fig, and its near relatives, along with other mites and scale-insects, but it is so ming with other mites and scale-insects, but it is so minute and dificult to distinguish with the insidcd eye that it was long thought to be the seed or bloom
of the plant itself. Leeuwenhöck, in 1703 , discovered of the plant itself. Leeuwenhöck, in 1703, discovered which never moved from a certain spot on the cactus, the male being the active member of the family but colorless and therefore useless. These insects are harvested three times during the dry season, being swept from the cacti into wide-mouthed bags with stiff from the cacti into wide-mouthed bags with stiff rhich they are dri packages for the market. In this thoroughly dried condition 70,000 insects are required to make a pound

The ornamental value of cacti, although important is not uppermost in the mind of the average inhabitant of arid regions. The trunks furnish him material for

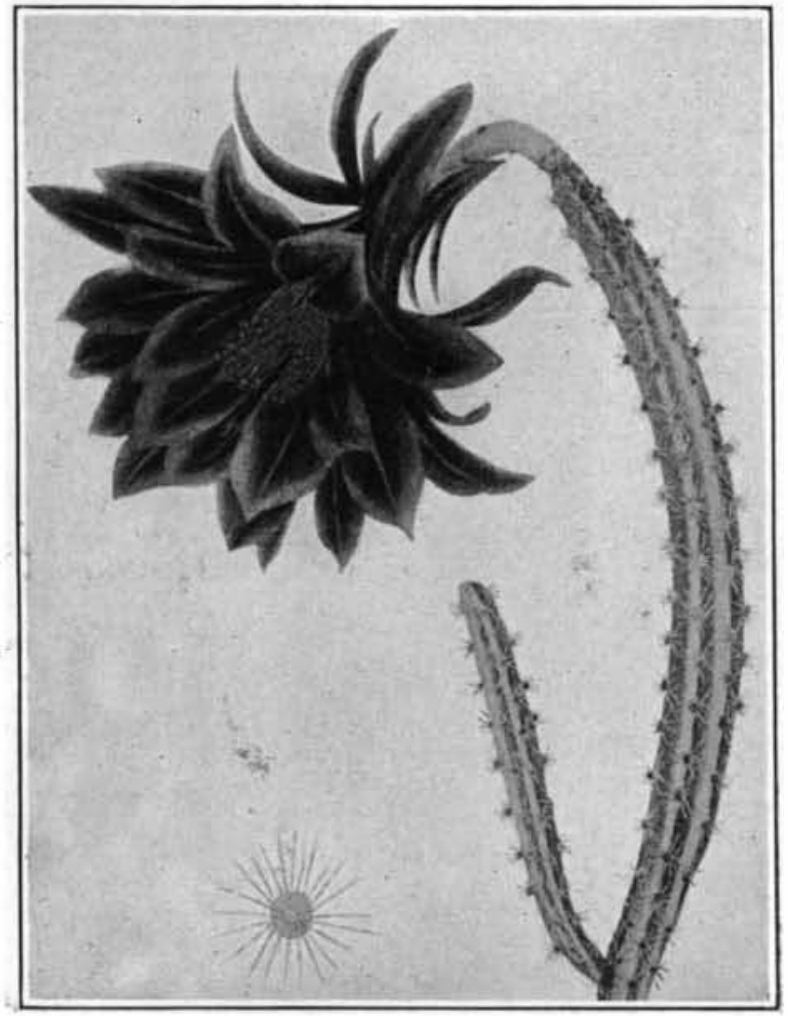

The splendid flower of Heliocereus Mallisoni

houses, corrals, firewood, ete., and, when planted close together they form hedges that are lasting and im: pervious. It is here behind a shield of thorns that the little cactus wren finds a refuge from hawks. where she can build her nest and rear her young in sacety. The cactus trunk is composed of a woody axis, or skeleton, surrounded by pulp. From this skeleton table legs, chairs, napkin rings, canes, veneerîng, etc. are made. The spines also are useful, serving as needles, toothpicks and pins for mending leather or cloth. Some are curved and supply ready-made fishhooks, while the straight ones are bound to slivers of bone to form very efficient barbs One species of and these have been used by the Indians for ages as hair brushes.

The pulpy parts of the stems and fruits are highly valuable as food both for man and beast. The young (Continued on page 499 )
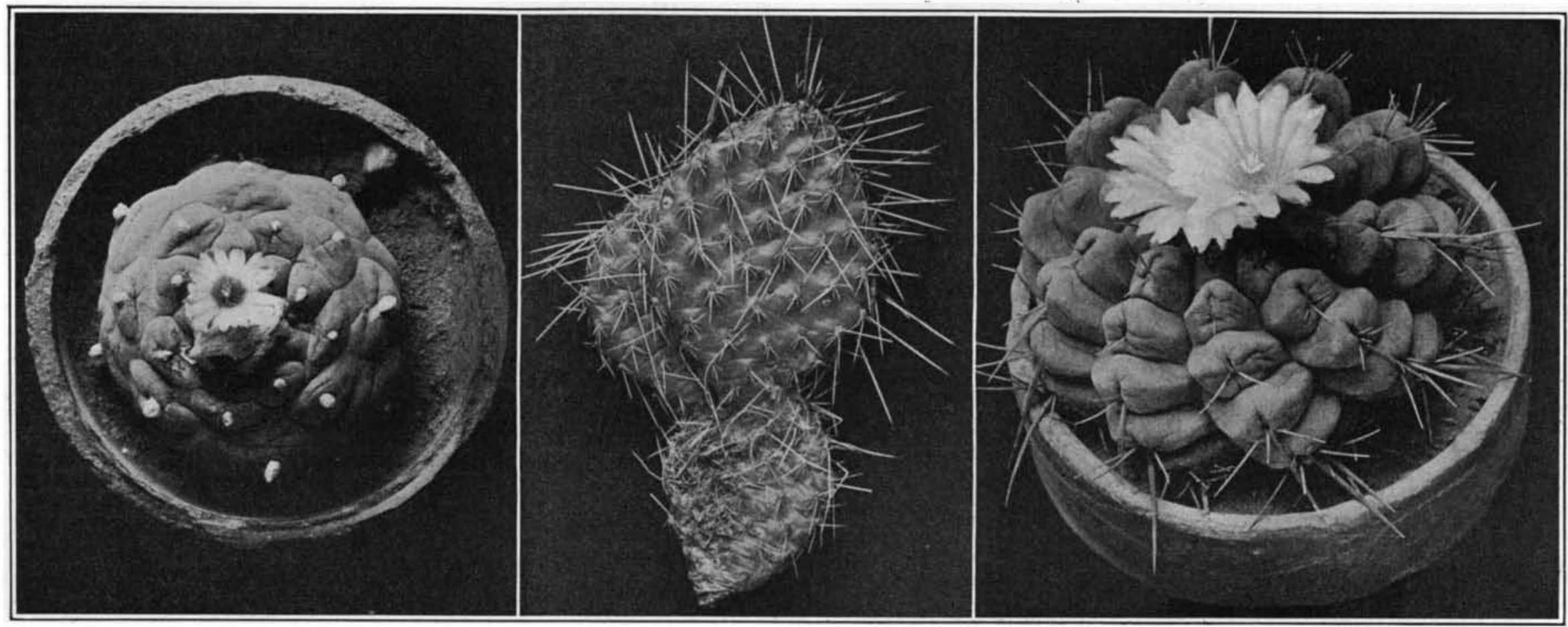

Left: The mescal button, or peyote, in flower. Center: A sneciee of Opuntia from Kansas. Right: A rather curious species of Echinocactus found in Mexico Several cacti of widely differing types 
less tractive effort than any other type of overlapping the other. A similar instance prevailing roadbed. Concrete structures on Langley Field is shown in the second will stand up under fire where stone view of page 490

buildings would be apt to succumb; and experiments have been made which reveal that gravel concrete columns can be rendered further immune to flame by coating them with plasters composed of gypsum, hydrated lime, and kieselguhr. And bitter experience has emphasized that the round concrete column is better able to endure intense heat or a blaze than one that is rectangular in section. In brief, a great deal has been learned latterly about concrete, and yet the investigator is busy seeking further enlightenment. The quest for knowledge is for the purpose of widening the ways in which concrete can be used confidently-eliminating the wh the hit-or-miss methods of the past.

\section{Making the Airplane Fireproof} (Continued from page 487 )

vents the fire from entering the helmet. A small window of two thicknesses of $1 / 8$ inch mica with $1 / 4$-inch air space is provided. The suit proper is made of $1 / 4$ inch sheet asbestos with a 3/8-inch inner lining of hair felt. Both shoes and gloves are made of the same material as the helmet is 15 pounds, but with a few refinements this could be brought down to about 10 pounds.

Because of the fireproof nature of an airplane treated by his process, Mr. Bradley has gone a step further and equipped aircraft with fireworks and flares for exhibition purposes. The wings, struts, turtle back, tail and other parts of a fireproofed plane are covered with fire works, and under the fuselage a dozen huge flares are mounted, all being wired for battery ignition, so that the pressing of a button by the pilot sets off all the freworks and flares at one time. The effect at night is, obviously, most spectacular-and absolutely safe, according to the inventor.

\section{The Craters of the Moon}

(Continued from page 491)

be a good deal of fractured and crumbled material in the ridges and peaks?

The bombs dropped on Langley Field were all of them moving at a much less speed than a representative meteoric body. Meteors are understood to enter the earth's atmosphere at velocities ranging, generally, between 10 and 40 miles pe
second. Such a body striking the moon' surface with its velocity unimpaired because of the absence of a substantial atmosphere would, Maj. Ives calculates, if mosphere would, Maj. Ives calculates, if all the heat generated be retained in the meteor, produce a temperature of $270,000^{\circ}$ F. This temperature would gasify al were dissipated into the materials surrounding the meteor; so that finally we should have an explosion. A military bomb will, accordingly, be a better experimental substitute for a meteor than perimental substitute for a common with non-explosive objects. In common with
the objects used in early experiments, the the objects used in early experiments, the bomb generates but little heat in the
surroundings at the moment of impact but, in contrast to them, it does imitate the explosive effects. The calculation of the temperature produced was based upon the minimum speed of 10 miles per second. The higher velocities would naturally produce still more excessive temperatures. One reaches the conclusion, then, that meteors behave upon impact much as do military bombs-that is, they give rise to an explosion.

The ability of a bomb to produce the central peak in a depressicn is shown very markedly in our third photograph. This is perhaps a more pronounced case than any on the moon itself. But the holes made on Langley Field are of all descriptions. Thus we have the extreme case of a crater floor free of projections, except perhaps close up at the foot of the circular cliff.

In our tinal picture we have the lunar cratersed. They are egg-shaped, two or n salads, preserves, pickled with lemons, dried, fermented as a beverage, made into a syrup called "tuna honey," a thin paste lar to guava jelly. Even the seeds are sometimes dried and saved to use when the fruits are gone.

The Barbados gooseberry, used for tarts and sauces in the West Indies, is appleshaped and decorated with small leaves or bracts. The plant, Pereskia aculeata, is a straggling shrub with slender brickles, glossy-green The prickly pears, or tunas, are abundant and much used. They are pearshaped or globular, weighing from an ounce to a pound; red, yellow, or purple in color; and usually sweet, though sometimes acid in flavor. The skin contains clusters of tiny spicules, or glochidia, the mouth, so that care is required in peeling them. They are sometimes called Indian figs or Barbary figs because of the numerous small seeds which they contivated for their fruits as well as for their edible joints. The flowers are large, usuDruits are those of Cereus grows to the height of sixty feet and its trunk reaches two and a half feet in diameter. The fruit is gathered at dawn with long reed sticks armed with several rongs.

The fruits of Cereus giganteus, a handsome cactus of the Southwest, are also much esteemed either in the fresh state or

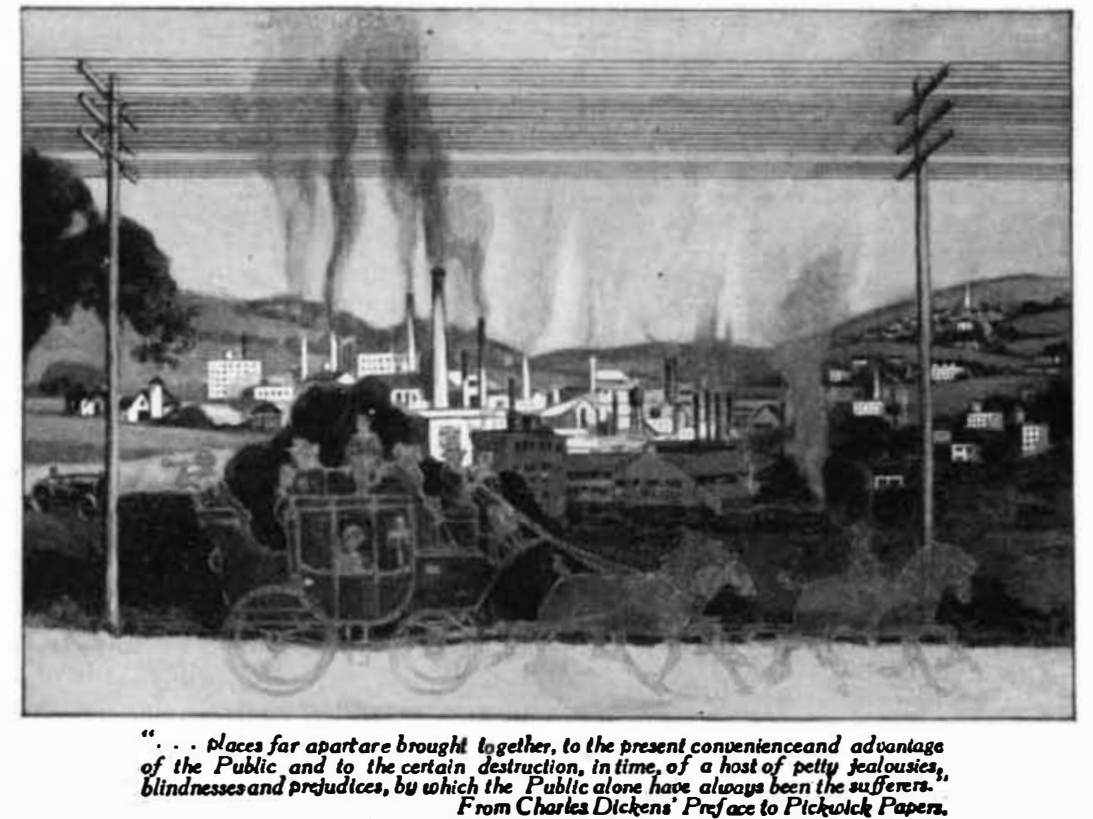

The Advance of Understanding
Even romance of sixty brief years ago could not imagine the great advance heralded by the passing of the stage coach. The railway and telegraph were coming into their own; but the telephone had not been so much as dreamed about.

Yet the wise men of that day saw the imperative need. They saw the value of every step which brought people into closer communication with each other. They knew this to be the one way to increase under- standing; and to eliminate the "host of petty jealousies, blindnesses and prejudices, by which the Public alone have always been the sufferers."

Then came the telephone. And with its coming time and distance are swept away and a hundred million people are made neighbors.

Places far apart are brought together by $34,000,000$ conversations a day over the Bell System. the surrounding air. They are also used tain. Several species of Opuntia are culyellow or orange, rarely rose or red.

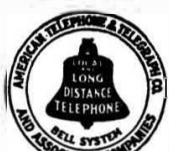

BELL SYSTEM"

American TElephOne AND TELEgRAPH COMPANy AND ASSOCIATED COMPANIES

One Policy, One System, Universal Service, and all directed toward Better Servico WELL DRILLING W PAYS
Own machine of your own. Cash or easy
terms. Many styles and sizes for all purposes Writc for Circular.

WILLAMS BROS., 434 W. State St., Ithaca, N., Y.
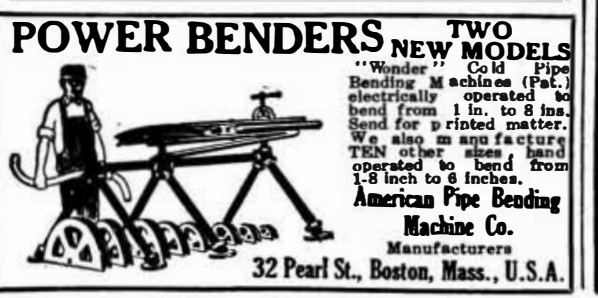
SCIENTIFIC AND TECHNICAL BOOKS

Listing 2500 titles on $\mathbf{5 0 0}$ subjects SELECTED from more than 7,000 Books still $\mathrm{S}$ in print. This catalogue is the latest and
best list of technical and scientific literature which can be secured. Conditions in the pub-
lishing business are most severe and it is with dificiculty that many books can be obtained. For this reason this timely catalogue of books
can be had will be par ticularly welcome. SCIENTIFIC AMERICAN PUBLISHING CO. Write to-day for your copy.
Sent free on application.

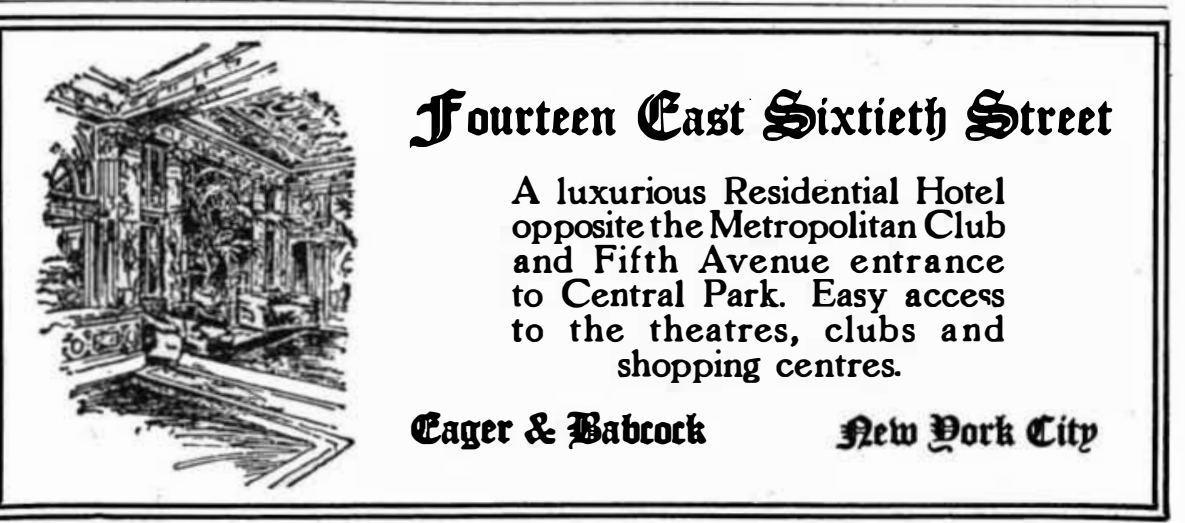


DURAND STEEL RACKS

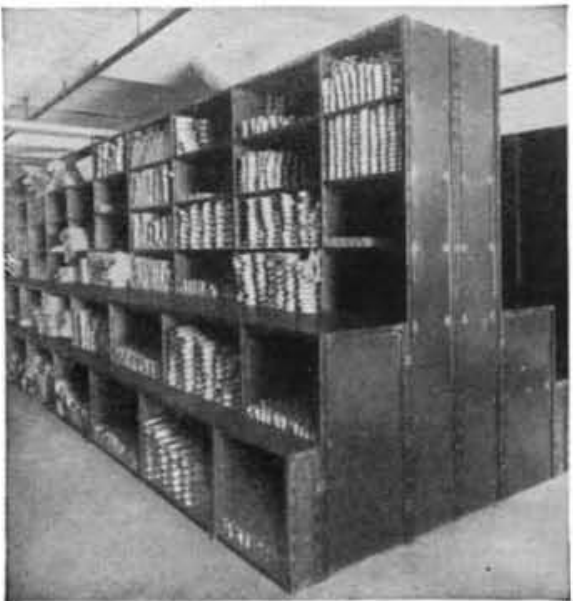

URAND Steel Racks
are not simply bins and shelving.

They are an essential adjunct of system in handling stocks of goods, keeping perpetual inventory, etc.

They are not mere metal; they are a method-a method so flexible that it will meet the fluctuating needs of practically any stock room.

Send for catalog of Darand Stcel
Lockers, or of Durand Steel Racks and Sheloing.

DuRand Steel Locker Co. 1574 Ft. Dearborn Bank Bldg. 574 Park Row Bldg.

For Gunsmiths, Tool Makers, Experimental \& Repair Work, etc.

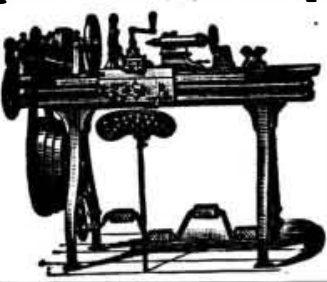

From 9-in. to 18-in. swing. Arranged to
Steam of foot Power
veam Velocipede or Stand up Treadle.

W. F. \& J. Barnes Co 1999 Ruby Street
Rockford. Ill.

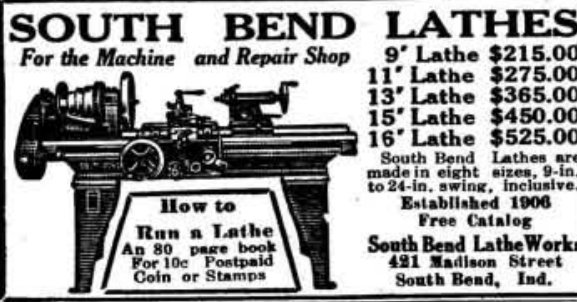

IHE SCHWERDTLE STAMP CO.

STEEL STANPS LETTERS \& FIGURES BRIDGEPORT CONK.

We Will Make It

Any thing in a metal stamping or novelty pro-
duced from any metal and finished in any color.

Waterbury Button Co., Waterbury, Conn

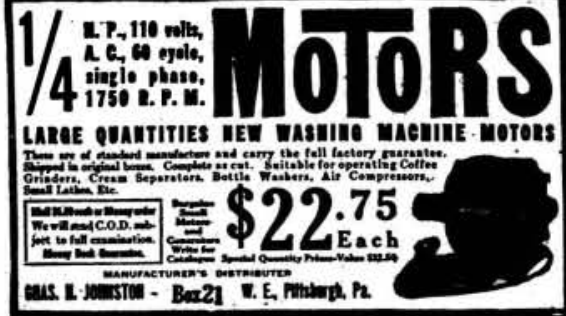

crimson. within. The strawberry pear, its tributaries on the other. Without clutobtained from Cereus triangularis, is pear- tering the map up with so many lines as
shaped, bright-red, with slightly acid to make it unintelligible we found it impulp, making it desirable in the fresh possible to do more than suggest the facts condition or as an ingredient of the "pepper pot" of the West Indies. Excellent fruits are also produced by Lemaireocereus thurberi and certain other large tree-cacti, and these "pitahayas" do not
have the annoying prickles found in the have the annoyin
fruits of Opuntia.

"Garambullas" are the small currantlike fruits of Myrtillocactus. They are eaten fresh or dried like raisins. The melon cacti produce a number of small edible fruits resembling tiny scarlet radishes or red peppers. The Mexican strawberry, found on a species of hedgehog cactus, is salmon-colored, two inches in length, and very sweet in flavor. It gets its name from its numerous minute seeds. Tetezo flgs, so important to the natives of southern Puebla, are the fruits of species of Pachycereus.

Although may of the wild cacti furnish valuable food for man and beast, it must be admitted that there is room for improvement both in the quantity and the quality of this food. I have visited Mr. Burbank's experimental grounds in California and fully realize the difficulty of his task in dealing with the cacti and the importance of his results. His problem was to take a vagrant, forbidding plant, and divest it of its thorns and prickles, breed out its indigestible woody skeleton and improve the size and flavor of its ruits

Of the twenty or more genera in the cacti he selected opuntia because it was soil and distributed, readily adaptable to ble pads and fruits, and already represented by some spineless varieties. He secured 75 species and 600 varieties of this genus from all parts of the world and selected from them plants that appeared to possess the greatest number of good qualities. Seeds from these plants were sown by the thousands and the new plants hybridized in order to break up their flxed habits. Gradually a few plants were ob-
tained by crossing and selection that were spineless. A After obtaining and fixing one good quality, he sought another and another, until, after ten years of very exacting labor, he gave to the world his "spineless cacti."

A number of these spineless forms, obtained from Mr. Burbank may be seen growing in the conservatories of the New York Botanical Garden. Some are especially suitable for feeding cattle, while others bear delicious fruits. Before the cuttings will grow they must be wilted in the hot sun for a week or more, after which they are partly buried in soil or ashes. When planted out in fields or or chards, they should be set three or four
feet apart in rows eight or ten feet apart. The fruits of these Burbank creations are over three inches long, usually yellow are over three inches long, usually yellow own, resembling those of peaches, melons, pineapples, etc. The amount of sugar is large, being 12 to 16 per cent which gives the fruits their sweetness and much of their food value. They may be sold for the price of oranges and it costs only half as much to grow them, while there
need be no fear of a poor or failing crop. need be no fear of a poor or failing crop. The food value of the spineless pads for stock is about half that of alfalfa, and
enormous crops can be grown without irrienormous crops can be grown without irri-
gation on arid or sterile land unsuited to other crops.

\section{Colorado's Cloud-Burst}

(Continued from page 494)

Pueblo, situated at the confluence of the Fountain and the Arkansas Rivers, got the ful
streams.

The map on page 494 shows the part of the Arkansas drainage system in which the flood had its origin. The contour lines are drawn for intervals of 250 feet. They indicate the great difference in pitch be- that the banks of these creeks are liketream, and that the latter is really bordered, below a ver than the water. We have been able to locate approximately one of the dams that broke; but the Geological. Survey maps, States or parts thereof, antedate the dams

Floods are nothing new to this region. Heavy rainfalls are common in the mountains, and it is a frequent occurrence to find the Arkansas occupying more or less mal banks and the foothills at either side. The extreme severity of the present visitation is due to the fact that many days of unusual rainfall were followed by the cloud-burst and the going out of the dams. The damage may be roughly divided un-
der three heads. Most of the loss of life was in the low parts of Pueblo, which were completely inundated, many houses being swept off their foundations by the occupants could make a move toward safety. Then the floor of the river valmouth of the canyon to Pueblo and be-
vond, is occupied by farms, which have suffered a great deal of damage to their standing crops as well as to their buildings. Finally, the railroads, building as they must along the line of the streams, while there has apparently been some loss of life from trains that were overtaken $y$ the flood and swept from the tracks. The floods at Denver and other points
in the northern part of the state appear in the northern part of the state appear of the streams under the influence of many days of rather steady, heavy rain. We read of no cloud-bursts in this secion, and of no dams going out. This is the reason why the floods here, while se-
vere enough, have not approached those vere enough, have not anproached those kansas River drainage system. But the Platte, which will eventually receive the flood waters from the northern part of or valley where it passes real channe braska than has the Arkansas through Kansas; so we may look for more serious secondary effects here than in the case of the Pueblo floods.

\section{The Farm Market for Trucks}

the size of the farm nor the type of farm ing has

"We believe we know fairly well why some farmers have bought trucks, but what about those who have not bough trucks? We want to know if this negabuying trucks, is there any possibility of buying trucks, is there any possibility of
showing them the real economy of this showing them the real economy of this
kind of hauling? With this in mind, we find thirty-three per cent of the farmers give as a reason for not buying trucks some reason that is classified as 'Finanroads and, incidentally, that is somewhat lower than we anticipated. We find that of those who say that they do not have the cash or credit with which to buy motor power for transportation, sixtytwo per cent own automobiles and eighteen per cent own tractors. In other money for the purchase of motor powe in some of its phases, but are not as yet sold on the fact that this is applicable to the transportation of their crops, though they recognize the value of portation or for use in plowing and harvesting the crops. wise steeper than those of the main cally all commercial maps of the practiley, as it gradually widens from the

\section{(Continued from page 495)}

"Of the farmers using trucks, forty-two per cent are using tractors. Here we find that the truck and tractor are not competitors as the smaller farmer is a less larger farmer, while the truck is equally applicable to all sizes of farms. The size of the truck best suited to farm use is a subject of much discussion among truck manufacturers and salesmen as well as armers.

"Regardless of the size of the farm, there is relatively little interest in a truck of less than one ton. We flnd from the who have not yet bought trucks, in the who have not yet bought trucks, in the wo-ton trucks. If we take this by the size of the farm, for example, we find forty-one per cent of them with farms of one hundred acres and less are interested in the one-ton truck. Of those farming over two hundred and forty acres, twentytwo per cent of them are interested in the one-ton truck, while only one per cent are interested in a truck of less than one ton. We flnd in the larger acreages thirty-nine per cent are interested in the two-ton truck, while twenty-six per cent of the farmers farming less than one hundred

\section{Labor-Saving Truck Bodies}

(Continued from page 495)

leys at each end of the tubular support, these cables being operated by means of gearing from the power take-off of the a load of . When the body is carrying position and the actuating member attached to the body frame is down at the lower end of the tubular support near the large sheave. When it is desired to dump a load of brick the engine power is diverted to the cross-shaft carrying the two large pulleys over which the cable runs, and as these pulleys rotate the body-actuating carriers are moved out on the tubuar supports and the body is shifted from the horizontal position it normally occu-
pies to the angular position necessary to dump its load. The construction outlined makes it possible to clear the rear end of the chassis with the body and have it assume a nearly vertical position so that the bricks may be deposited on the ground in the same orderly way in which they were loaded into the truck body.

Another use of the power take-off is outlined in the photograph of the $21 / 2$-ton truck which is equipped with a special log loader which makes it possible for one man to load or unload large logs unaided, except for the engine power, that would require a gang of men to handle with the simple skid equipment ordinarily provided for lumbering operations. The log-loading mechanism is very simple. It consists of a windlass roll carried at the side of the chassis by suitable bearings and extending from the cab to the rear end. The $\log$ to be loaded is encircled by a chain, the end of which is attached to one of the hooks on the windlass. When the engine power is diverted to the windlass-operat ing gear by the simple foot-pedal control, mounted on one of the steps, the chains roll up and drag the logs up the skidway and on to the truck frame.

Another simple device which saves con siderable time is fitted to a truck of the Kansas City, Mo., Telephone Company. This truck is equipped with a simple hoist or derrick for raising and setting telephone poles. Recently the truck and a gang of three men, one of whom was 
A Money-Saver in Locomotive Repair

F VERY steam locoE motive carriès from four to twenty-eight bearing boxes for the truck and driving wheels. Each of these boxes has a hubliner-a metal disk protecting metal disk protecting the friction of the wheel hub. This hubliner is ordinarily cast on from babbitt metal, by means of an operation that is difficult and dangerous for the machinist and
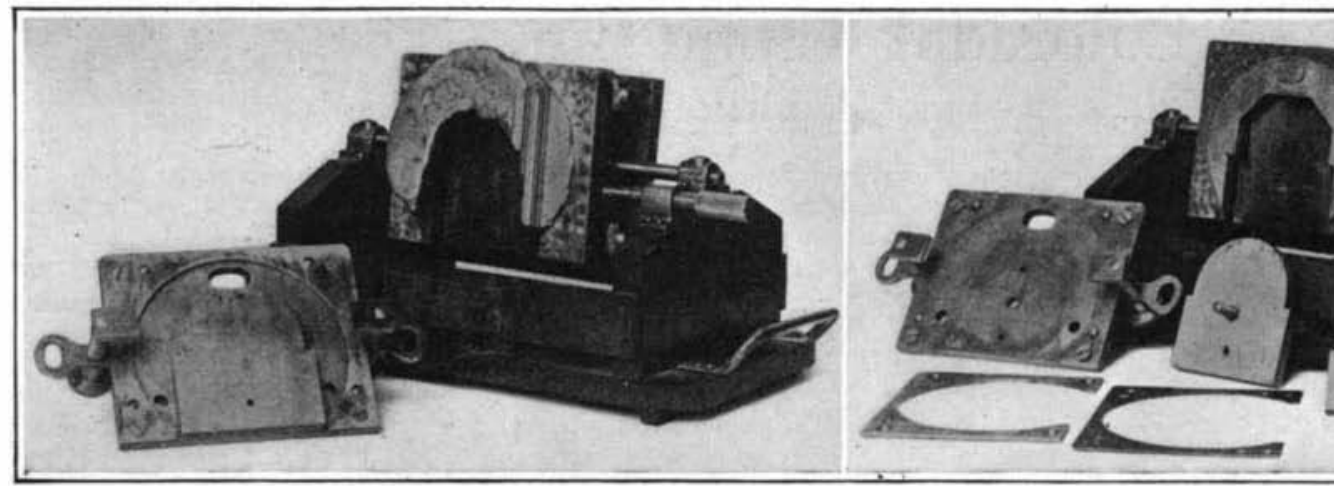

Left: The old method, showing how much metal was wasted. Right: A hubl

The new outfit for casting locomotive hubliners at great saving of men and metal words or syllables is convention; that it is just as sensible to carry a word over at any point. Accordingly the difficulties of justification, which we emphasized in our issue of December 13, 1919, do not exist for him-he runs merrily along, and moves over to the beginning of the next line whenever his copy
brings him to the end of this line.

Mr. Backes has recently been experimenting a little further in ing a little further in inordinately costly to box with a chain hoist and put it in a fire pot, where it must remain half an hour before becoming hot enough. When it attains this point it is again hoisted out of the fire and put on the floor, where a workman builds a wall inside and out of fire clay, large enough to cast on a two-inch liner. After some five hours the box has cooled sufficiently for it to be moved into the machine shop. Here the babbitt is shaved off to the proper thick. ness, the shavings falling to the floor and mixing with the iron and steel scraps which lie there, making necessary a separating process before the latter can be used. The babbitt scrap is waste pure and simple, since a second heating renders it second class metal. After this planing the box is carried to the locomotive erecting shop, where the necessary holes are drilled for assembling it on the enginea difficult task, and one invariably resulting in loss of one or more drills. The entire process requires the services of five men and extends over two to three days.

A Newark, N. J., machinist has devised a hubliner mold that eliminates all this It makes possible the installation of a hubliner within an hour and a half. No heating, soldering or fireclaying is required. The lubricating holes are cast direct in the liner, saving all drilling. The liner can be cast right on the cold box at the point where it is taken from the wheel, so there is no chain-hoisting or other moving of the work about. Although cast on the cold box without soldering, the inventor guarantees that the liner will not come off. He points out that when cast this way the liner has a "skin," which is nōt the case where it has to be shaved off; the period of renewal becomes a year instead of six months.

The apparatus by which all this improvement is attained is simple enough Our photograph shows it after it has been
taken down off the completed liner, which is seen as recognize the name, callitypy, which he has given to imm cast on the box. It will be at once understood how the his system. He boldly takes the bull by the horns in pattern is clamped to the backpiece, and the latter the matter of typewritten text, and insists that the turned over and clamped to the end of the box, pre- only reason for having the lines come out with even liminary to the casting. Patterns of $\mathrm{v}$ a r i o u $\mathrm{s}$ Patterns of $\nabla$ a ri o u s
shapes and sizes may be shapes and sizes may be
used with the single. used with the single.
back-piece to produce liners of any desired model.

Ornamental Typewriting

$A^{T}$ the time, a year A ago last fall, when the editorial typewriters kept the Scientific American in the ring while most of our contemporaries were suspended because of the compositors' and pressmen's strike, none our readers was more our readers was more than Mr. Jacob Backes, of this city. Mr. Backes has for some years been interested in the possi-
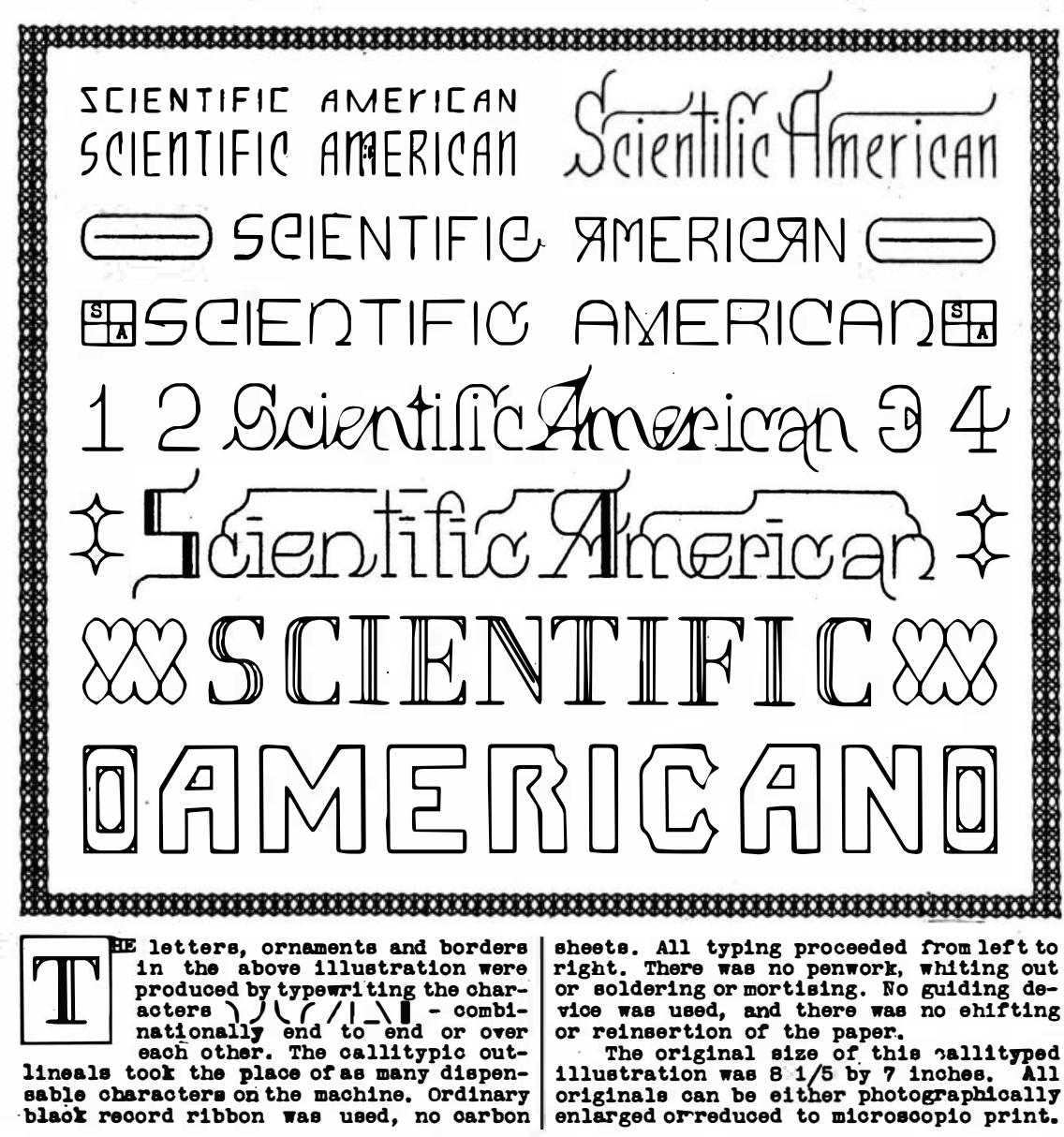

A sample of what can be done with a typewriter equipped with a few special keys
sith a typew

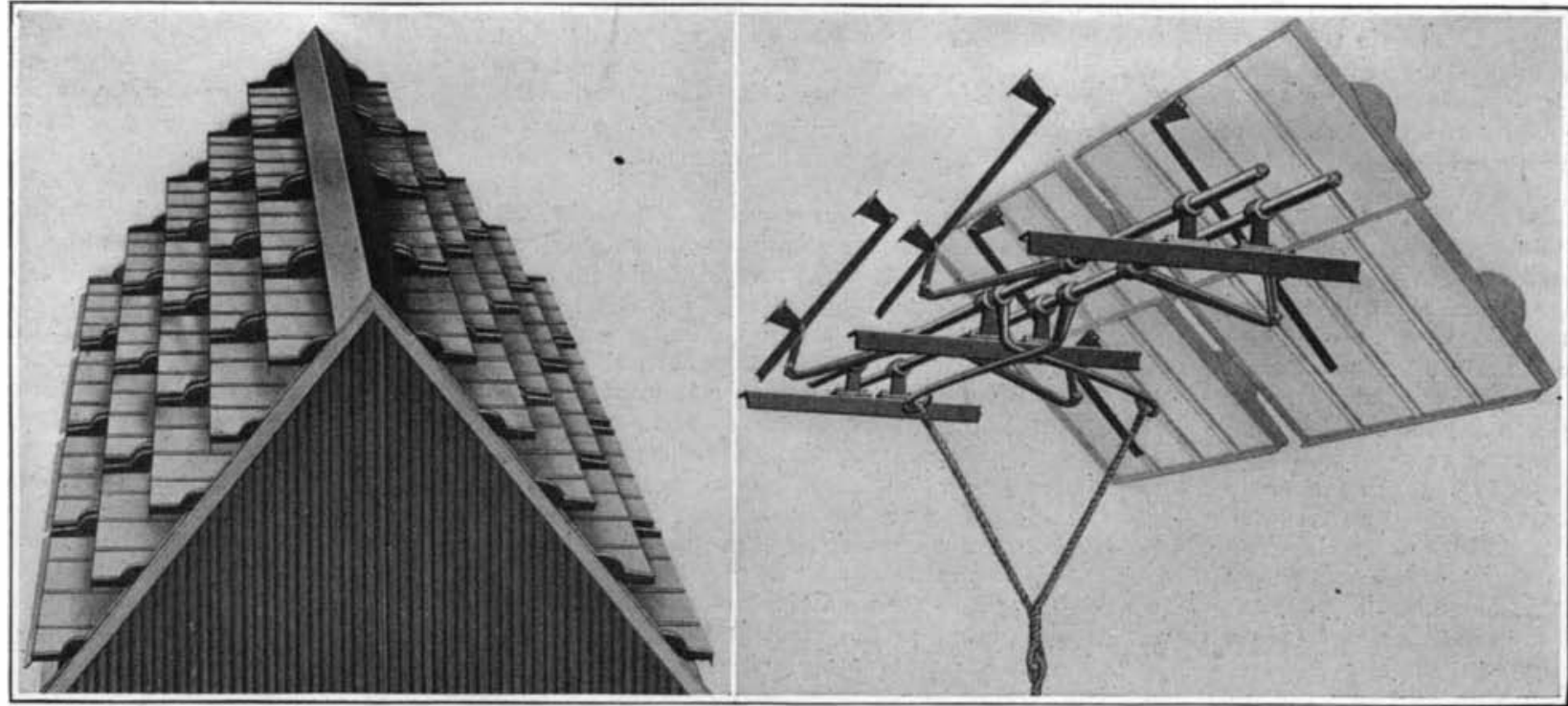

The automatic ventilating skylight, showing how it looks when open, and means for controlling it immediately self-opening when the control is released. This control may be by hand; or if it is desired that the skylight open as a means of release of smoke and fumes from fire, it may be held in closed position by a fusible link or an in. flammable rope, to be automatically released when this gives way. The explanation that the new ventilator is designed largely for use in theaters explains what might otherwise be somewhat of a puz. zle-why it is desired to give a fire exit to the outer air.

The construction is such that the device can be used as a lean-to ventilator and skylight, or placed in any other way. When closed, one sash overlaps the next by several inches, with a nosing at the top of the under sash to keep out any water that might be driven up by a rain storm. 